\title{
Medicinal Potentials of Extracts of Nanoparticles Synthesized from the Stem Bark and Roots of Rourea Minor (Santaloides afzelii)
}

\author{
Terver John Sase ${ }^{*}$, Yilni Edward Bioltif ${ }^{1}$, Philomena Ayika ${ }^{2}$, Wushiba Habila Gorip ${ }^{1}$, Job Dawulung ${ }^{1}$ \\ 1'Department of Chemistry, Plateau State University, PMB 2012 Bokkos, Plateau State, Nigeria \\ ${ }^{2}$ Department of Microbiology, Plateau State University, PMB 2012 Bokkos, Plateau State, Nigeria
}

\begin{abstract}
*Address for Correspondence: Dr. Terver John Sase, Lecturer II/Teaching and Research, Department of Chemistry, Faculty of Natural and Applied Sciences, Plateau State University, PMB 2012, Bokkos, Plateau State, Nigeria

E-mail: terversase@gmail.com
\end{abstract}

Received: 25 Jan 2020/ Revised: 26 Mar 2020/ Accepted: 28 Apr 2020

\begin{abstract}
Background: Human disease management in Nigerian history provides evidence of the relationship between plants and medicine. However, research and development of medicinal plants have not advanced to the stage of impacting positively on the health system in Nigeria like other advanced countries, thus, the need for this research.

Methods: Stem and roots were screened for phytochemicals. The UV-VIS profile of methanolic extract of Santaloides afzelii (S. afzelii) was taken at the wavelength of $200 \mathrm{~nm}$ to $1200 \mathrm{~nm}$. AgNPs and crude extracts were used for Anti-microbial test on the following organisms Klebsiella pneumonia, Escherichia coli, Shigella sp., Staphylococcus aureus and Salmonella typhi.

Results: Methanol extracts for both Stem and roots gave the highest yields. All the phytochemicals that were present in at least one or more solvent extract in the stem and root extracts, alkaloids and steroids were present in all the solvent extract of the stem bark, while coumarin was present in all the solvent extract of the roots. Inhibition of the tested bacteria occurred more from the synthesized nanoparticles of the extracts and their respective extracting solvents except for Klebsiella sp. The UV-VIS profile of the methanol extract showed the peaks at $220 \mathrm{~cm}^{-1}$ and $260 \mathrm{~cm}^{-1}$, with the maximum absorptions at 2.59 and 1.55 , respectively.

Conclusion: This study revealed that AgNPs of $S$. afzelii stem and root extracts possess medicinal properties and antibacterial activity that inhibit bacterial growth.
\end{abstract}

Key-words: Antimicrobial activity, Phytochemicals, Santaloides afzelii, Silver nanoparticles

\section{INTRODUCTION}

Herbal medicine is still the mainstay of about $75-80 \%$ of the world population, mainly in developing countries, for primary health care ${ }^{[1]}$. The use of plants as a source of remedies for the treatment of diseases dates back to prehistory and people of all continents have this old tradition, despite the remarkable progress in synthetic organic chemistry of the twentieth century, over $25 \%$ of prescribed medicines in industrialized countries are derived directly or indirectly from plants ${ }^{[2]}$. Human disease management in Nigerian history also

\section{How to cite this article}

Sase TJ, Bioltif YE, Ayika P, Gorip WH, Dawulung J. Medicinal Potentials of Extracts of Nanoparticles Synthesized from the Stem Bark and Roots of Rourea Minor (Santaloides afzelii). SSR Inst. Int. J. Life Sci., 2020; 6(3): 2557-2564.

Access this article online
https://iijls.com/

provides evidence of the relationship between plants and medicine ${ }^{[3]}$. However, research and development of medicinal plants have not advanced to the stage of impacting positively on the health system in Nigeria like other African countries ${ }^{[4]}$. Plants produce a remarkably diverse array of over 500,000 low molecular mass natural products also known as secondary metabolites. Phytochemical components are responsible for both pharmacological and toxic activities in plants. These metabolites are said to be useful to the plant itself, but can be toxic to animals including man, which can be explored for medicinal purposes ${ }^{[5]}$.

S. afzelii belongs to the plant family Connaraceae. The Connaraceae family consists of about 20 genera and 350 species of titaniferous tropical trees and shrubs ${ }^{[6]}$. It is a shrub or small tree, widely dispersed in tropical Africa and used in ethnomedicine for the treatment of diverse ailments ${ }^{[7]}$. Ishola et al. ${ }^{[8]}$ reported that the leaves in this family are alternate, without stipules and pinnate 
compounds. The plants of this family possess analgesic and anti-inflammatory activities. Polyphenols compounds, including anthocyanins, flavonols, and phenolic acids, and are among the most bioactive natural molecules found in the plants because of their antioxidant activities ${ }^{[9]}$. The risk of prostate cancer and pancreatic cancer may decrease at higher dietary flavonoids intakes ${ }^{[10]}$.

In tropical countries, particularly in Côte d'lvoire, $S$. afzelii is often used in traditional medicine by villagers ${ }^{[11]}$. The present report identifies the medicinal potentials of the roots and stem of the herbal plant S. afzelii.

\section{MATERIALS AND METHODS}

The study was performed at the Laboratory of Chemistry and Laboratory of Microbiology, Plateau State University, Bokkos from September 2017 to February 2019.

Identification and Collection of plant material- S. afzelii roots and stem back were collected from Federal college of forestry Jos at Jos North LGA of Plateau State (Nigeria). The plant was identified by a staff of the institution by name Mr Yusuf Umar.

Plant material preparation- The roots and stem back obtained from the plant was dried at room temperature for four (4) weeks, after which it was pulverized into a moderately coarse powder (using a wooden pestle and mortar) and stored in a closed container until further analysis ${ }^{[12]}$.

Preparation of Extract- Total $800 \mathrm{~g}$ of each powdered roots and stem back were soaked in $2000 \mathrm{ml}$ of three solvents ( $\mathrm{n}$-Hexane, Ethyl acetate and Methanol) for 72 hours ( 3 days), with occasional stirring using a magnetic stirrer to ensure proper mixture of the vessel content. The content was then filtered using a sintered funnel, (which is equivalent to four folds of bandage). The extract (filtrate) was then concentrated using a rotary evaporator. This was then weighed and used for the analysis. The percentage yield was calculated using the formula below ${ }^{[13]}$.

Yield $(\%)=\frac{\text { Weight of the dry concentrated crude extract }}{\text { Weight of the dried crushed plant sample used }} \times 100$

Phytochemical Screening- The methods described below were used to assess the phytochemical constituents of the crude plant extracts (both the roots and stem back of S. afzelli) ${ }^{[13]}$.
Test for Saponins- Total $2 \mathrm{~mL}$ of crude extracts of $S$. afzelli were shaken vigorously with $5 \mathrm{ml}$ of distilled water in a test tube and warmed. The formation of stable foam was taken as an indication of the presence of saponins.

Test for Alkaloid- A fraction of crude extracts of S. afzelli were treated with Wagner's test reagent (1.27 g of iodine and $2 \mathrm{~g}$ of potassium iodide in $100 \mathrm{ml}$ of water) and observed for the formation of a reddish-brown colour precipitate.

Test for Tannins- The crude extract of $S$. afzelli was stirred with $10 \mathrm{~mL}$ of distilled water and then filtered. Few drops of $5 \% \mathrm{FeCl}_{3}$ reagent was added to the filtrate. Blue-black, blue-green coloration and precipitation were taken as an indication of the presence of tannins.

Test for Phenols- Total $2 \mathrm{~mL}$ of the crude extracts were taken into $10 \mathrm{~mL}$ of water and warmed at $50^{\circ} \mathrm{C}$. Then $2 \mathrm{ml}$ of $3 \% \mathrm{FeCl}_{3}$ ration of green or blue colour indicated the presence of phenols.

Tests for Steroids- Development of a greenish colour when $2 \mathrm{ml}$ of the crude organic extract was dissolved in 2 $\mathrm{ml}$ of chloroform and treated with sulphuric and acetic acid indicated the presence of steroids.

Keller-Killiani test for Glycosides- A total of $1 \mathrm{~mL}$ of glacial acetic acid, few drops of ferric chloride solution and conc. $\mathrm{H}_{2} \mathrm{SO}_{4}$ (slowly through the sides of the test tube) was added to the extracts. The appearance of the reddish-brown ring at the junction of the liquids indicated the presence of deoxy sugars.

Alkaline reagent test for Flavonoids- Extract was treated with $10 \% \mathrm{NaOH}$ solution; the formation of intense yellow colour indicated the presence of Flavonoid.

Test for Phlobatannins- Total $1 \mathrm{~mL}$ extract was boiled with $2 \mathrm{ml}$ of $1 \%$ hydrochloric acid. The red precipitate signified the presence of Phlobatannins.

Test for Anthraquinones- Total $2 \mathrm{~mL}$ of the crude extracts' solution was hydrolyzed with Conc. $\mathrm{H}_{2} \mathrm{SO}_{4}$ extracted with benzene. Total $1 \mathrm{ml}$ of dilute ammonia was added to it. Rose pink colouration suggested a positive response for anthraquinones.

Test for Coumarin- Three (3) $\mathrm{ml}$ of $10 \% \mathrm{NaOH}$ was added to $2 \mathrm{ml}$ of extract formation of yellow colour indicated the presence coumarins. 
Synthesis of Silver Nanoparticles- In the green synthesis of AgNPs, $0.01 \mathrm{M}$ of an aqueous solution of $\mathrm{AgNO}_{3}$ (99.99\%) was used. Total $5 \mathrm{~mL}$ of root broth was added to $45 \mathrm{~mL}$ of $0.01 \mathrm{M} \mathrm{AgNO}_{3}$ aqueous solution and allowed at the ambient condition to react. After different time intervals, the colour change of the reaction mixture was observed from transparent yellow to dark brown indicating the formation of AgNPs ${ }^{[22]}$.

UV-Visible spectral analysis- AgNPs root extract was subjected to UV Visible spectral analysis. The extracts were centrifuged at $3000 \mathrm{rpm}$ for $10 \mathrm{~min}$ and filtered through Whatman No. 1 filter paper for UV and spectrophotometer analysis by using a high-pressure vacuum pump. The sample was diluted to $1: 10$ with the same solvent. The extracts were scanned in the wavelength ranging from 300-1200 nm using Perkin Elmer Spectrophotometer and the characteristic peaks were detected ${ }^{[14]}$.

Tests for Anti-microbial activity- The antimicrobial activities of this extract were determined using some human pathogens, which were obtained from the Department of Microbiology, Plateau State University, Bokkos. All the pure culture of the test organisms were sub-cultured for 24 hours and 2 hours respectively in broth agar. The crude extracts of $S$. afzelii $(0.4 \mathrm{~g})$ and AgNPs were weighed and dissolved in $5 \mathrm{ml}$ of sterile water to obtain a concentration of $80 \mathrm{mg} / \mathrm{ml}$ and were serially diluted to $40 \mathrm{mg} / \mathrm{ml}, 20 \mathrm{mg} / \mathrm{ml}$ and $10 \mathrm{mg} / \mathrm{ml}$ of the different concentrations of the extract was aseptically dispensed in each of the well using pasteurized pipette ${ }^{[15]}$. Nutrient agar was the medium used as the growth medium for the test microbes. The medium was prepared according to the manufacturer 's instruction, sterilized at $121^{\circ} \mathrm{C}$ for 15 minutes in the autoclave, poured in 12 (10 dishes for the five duplicate organisms, 1 dish for media sterility control MSC and the other for Organism Validity Control (OVC) sterile Petri dishes and was allowed to cool and solidify. The inoculated medium was incubated at $37^{\circ} \mathrm{C}$ for 24 hours, after which each plate was observed in the zone of inhibition of growth. The zone was measured with a transparent ruler and the result was recorded in centimetres. The following were the organisms obtained and tested; S. aureus, E. coli, Klebsiella sp., Shigella, and S. Typhi ${ }^{[12]}$.

\section{RESULTS}

The results obtained are presented in the Tables and Figures as shown below. Table 1 and Fig. 1 represent the percentage yields of the extracts showing the details of the weights taken for both the stem bark and roots of $S$. afzelii, HE stands for the Hexane Extract of roots and stem, EE stands for the Ethyl acetate Extract of the stem and roots while ME represents the Methanol Extracts of the stem and roots of the plant under studies in the present work. The root extracts gave the highest yields in all the solvent systems as indicated by Fig. 1.

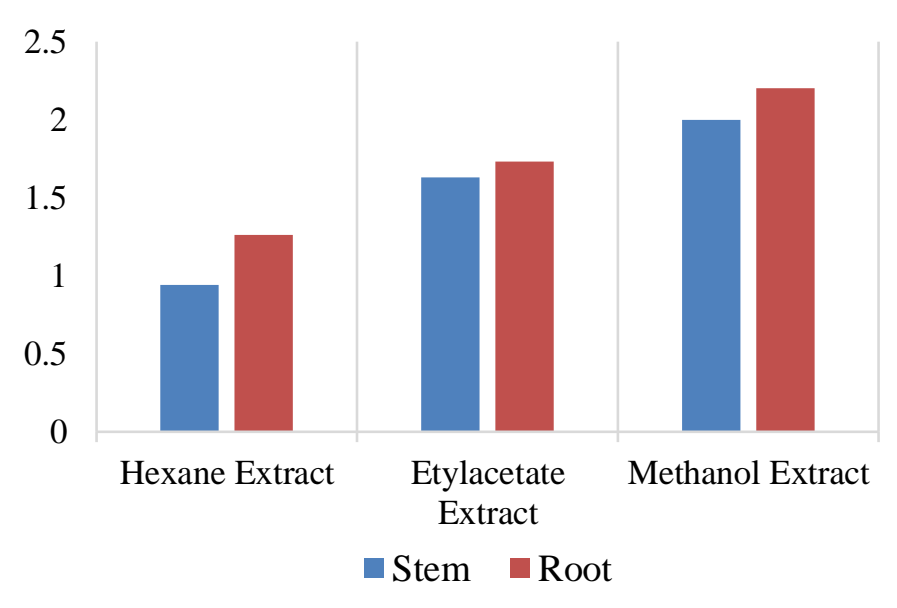

Yield (\%)

Fig. 1: Percentage Yield of stem and root extract

Table 2 represents the result of phytochemical analysis of the crude extracts of the stem and roots of S. afzelii. The positive sign indicates presence of the phytochemicals while the negative sign indicated the absence of the phytochemicals. Methanol extract showed the presence of almost all the phytochemicals tested except in for Flavonoids that were absent in the roots, Alkaloids absent in roots, Glycosides absent in the stem and steroids absent in the roots. Methanol showed to be a better solvent for the extraction than Ethyl acetate and Hexane. 
Table 1: Weight and percentage yield of crude extracts of S. afzelii

\begin{tabular}{ccccc}
\hline Extracts & Plant parts & Wt. of samples $(\mathbf{g})$ & Wt. of extracts $(\mathbf{g})$ & Yield $(\%)(\mathbf{w} / \mathbf{w})$ \\
\hline $\mathrm{HE}$ & Stem & 800 & 7.50 & 0.94 \\
& Root & 800 & 10.10 & 1.26 \\
$\mathrm{EE}$ & Stem & 800 & 13.00 & 1.63 \\
& Root & 800 & 13.80 & 1.73 \\
$\mathrm{ME}$ & Stem & 800 & 16.00 & 2.00 \\
& Root & 800 & 17.60 & 2.20 \\
\hline
\end{tabular}

HE: Hexane extract, EE: Ethylacetate extract, ME: Methanol extract

Table 2: Qualitative phytochemical screening of S. afzelii

\begin{tabular}{|c|c|c|c|c|c|}
\hline S.No. & Phytochemicals & Plant parts & n-Hexane & Ethyl acetate & Methanol \\
\hline \multirow[t]{2}{*}{1} & Saponins & Stem & - & - & + \\
\hline & & Root & + & - & + \\
\hline \multirow[t]{2}{*}{2} & Tannins & Stem & - & - & + \\
\hline & & Root & - & - & + \\
\hline \multirow[t]{2}{*}{3} & Phenols & Stem & - & - & + \\
\hline & & Root & - & - & + \\
\hline \multirow[t]{2}{*}{4} & Flavonoid & Stem & - & + & + \\
\hline & & Root & + & - & - \\
\hline \multirow[t]{2}{*}{5} & Coumarin & Stem & - & + & + \\
\hline & & Root & + & + & + \\
\hline \multirow[t]{2}{*}{6} & Alkaloid & Stem & + & + & + \\
\hline & & Root & + & - & - \\
\hline \multirow[t]{2}{*}{7} & Anthraquinone & Stem & - & - & + \\
\hline & & Root & - & + & + \\
\hline \multirow[t]{2}{*}{8} & Phlobatanins & Stem & - & - & + \\
\hline & & Root & - & - & + \\
\hline \multirow[t]{2}{*}{9} & Glycosides & Stem & - & - & - \\
\hline & & Root & - & - & + \\
\hline \multirow[t]{2}{*}{10} & Steroid & Stem & + & + & + \\
\hline & & Root & + & + & - \\
\hline
\end{tabular}

+: Present, -: Absent

Tables 3 and Fig. 2 shows the results of antimicrobial analysis showing zones of inhibition against the test pathogens for the Crude extracts and synthesized AgNPs for the Stems of the plant under study in the present work. All the text using the synthesized AgNPs showed better zones of inhibition compared to their corresponding crude extracts as indicated below: 
Table 3: Showing zone of inhibition by S. afzelii stem

\begin{tabular}{|c|c|c|c|c|c|}
\hline \multirow{2}{*}{ S.No. } & \multirow{2}{*}{ Bacterial sp. } & \multirow{2}{*}{ Samples } & \multicolumn{3}{|c|}{ Zone of Inhibition (mm) } \\
\hline & & & n-Hexane & Ethyl acetate & Methanol \\
\hline \multirow{2}{*}{1} & \multirow{2}{*}{ E. coli } & $\mathrm{CE}$ & 15 & 19 & 19 \\
\hline & & AgNPs & 20 & 23 & 20 \\
\hline \multirow{2}{*}{2} & \multirow{2}{*}{ Shegilla sp. } & CE & 17 & 19 & 14 \\
\hline & & AgNPs & 20 & 23 & 21 \\
\hline \multirow{2}{*}{3} & \multirow{2}{*}{ S. typhi } & CE & 19 & 23 & 15 \\
\hline & & AgNPs & 25 & 24 & 25 \\
\hline \multirow{2}{*}{4} & \multirow{2}{*}{ Klepsiella sp. } & $\mathrm{CE}$ & 21 & 22 & 12 \\
\hline & & AgNPs & 20 & 22 & 14 \\
\hline \multirow{2}{*}{5} & \multirow{2}{*}{ S. aureus } & CE & 22 & 19 & 21 \\
\hline & & AgNPs & 24 & 21 & 25 \\
\hline
\end{tabular}

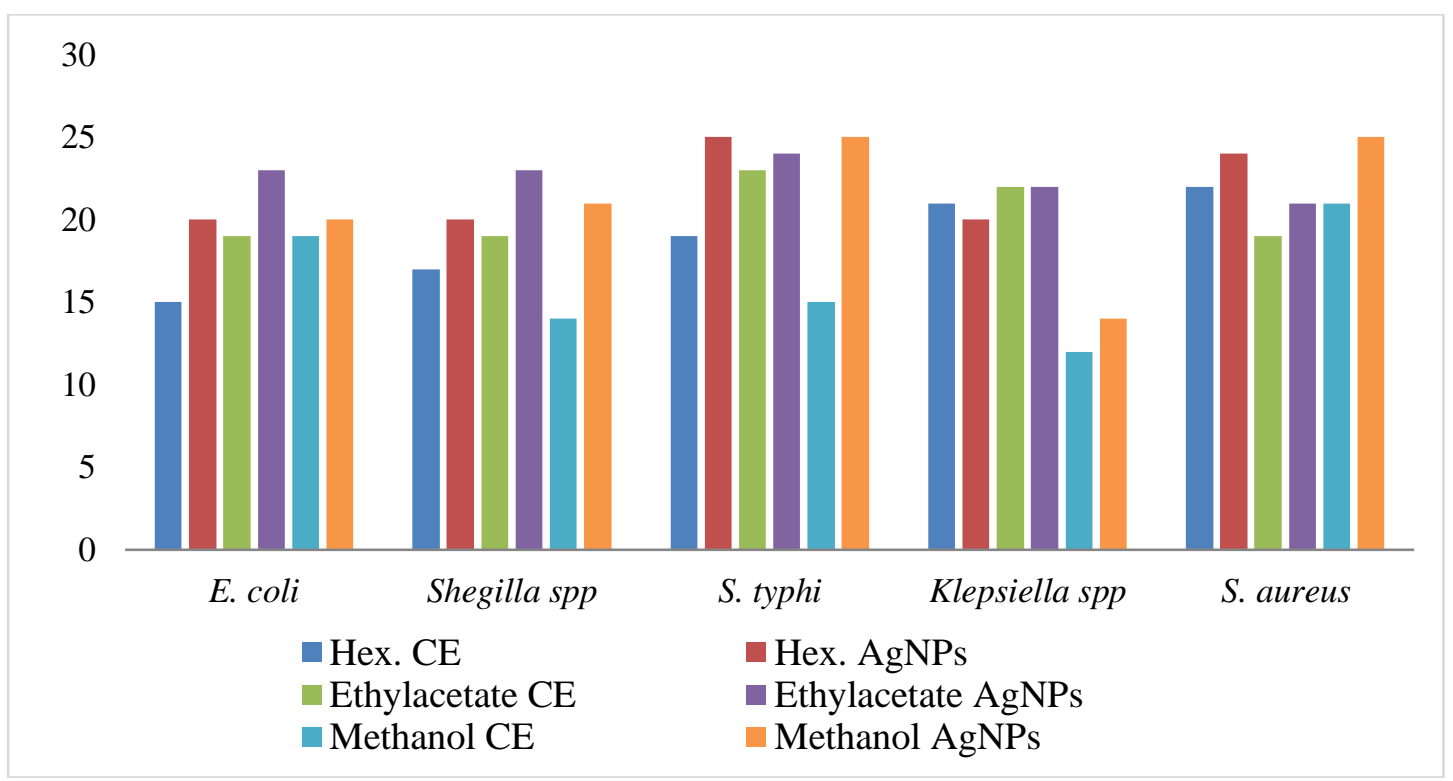

Fig. 2: Zone of Inhibition by the stem of S. afzelii

Table 4 and Fig. 3 represent the result of antimicrobial analysis on the test organisms using crude extracts and synthesized AgNPs of the roots of the plant under study. Both samples showed effects on the test organism but the synthesized AgNPs showed better zones of inhibition compared to the crude extracts and Fig. 4 represents the UV-Vis. spectra of the synthesised AgNPs of the root extracts of the plant in the present study.

Table 4: Showing zone of inhibition by S. afzelii Roots

\begin{tabular}{|c|c|c|c|c|c|}
\hline \multirow[b]{2}{*}{ S.No. } & \multirow[b]{2}{*}{ Bacterial sp. } & \multirow[b]{2}{*}{ Samples } & \multicolumn{3}{|c|}{ Zone of Inhibition (mm) } \\
\hline & & & n-Hexane & Ethyl acetate & Methanol \\
\hline \multirow[t]{2}{*}{1} & E. coli & CE & 22 & 23 & 19 \\
\hline & & AgNPs & 24 & 25 & 20 \\
\hline \multirow[t]{2}{*}{2} & Shegilla sp. & CE & 17 & 25 & 17 \\
\hline & & AgNPs & 23 & 30 & 25 \\
\hline \multirow[t]{2}{*}{3} & S. typhi & CE & 19 & 20 & 18 \\
\hline & & AgNPs & 27 & 31 & 24 \\
\hline \multirow[t]{2}{*}{4} & Klepsiella sp. & CE & 21 & 24 & 19 \\
\hline & & AgNPs & 22 & 25 & 20 \\
\hline \multirow[t]{2}{*}{5} & S. aureus & CE & 22 & 21 & 21 \\
\hline & & AgNPs & 28 & 31 & 25 \\
\hline
\end{tabular}




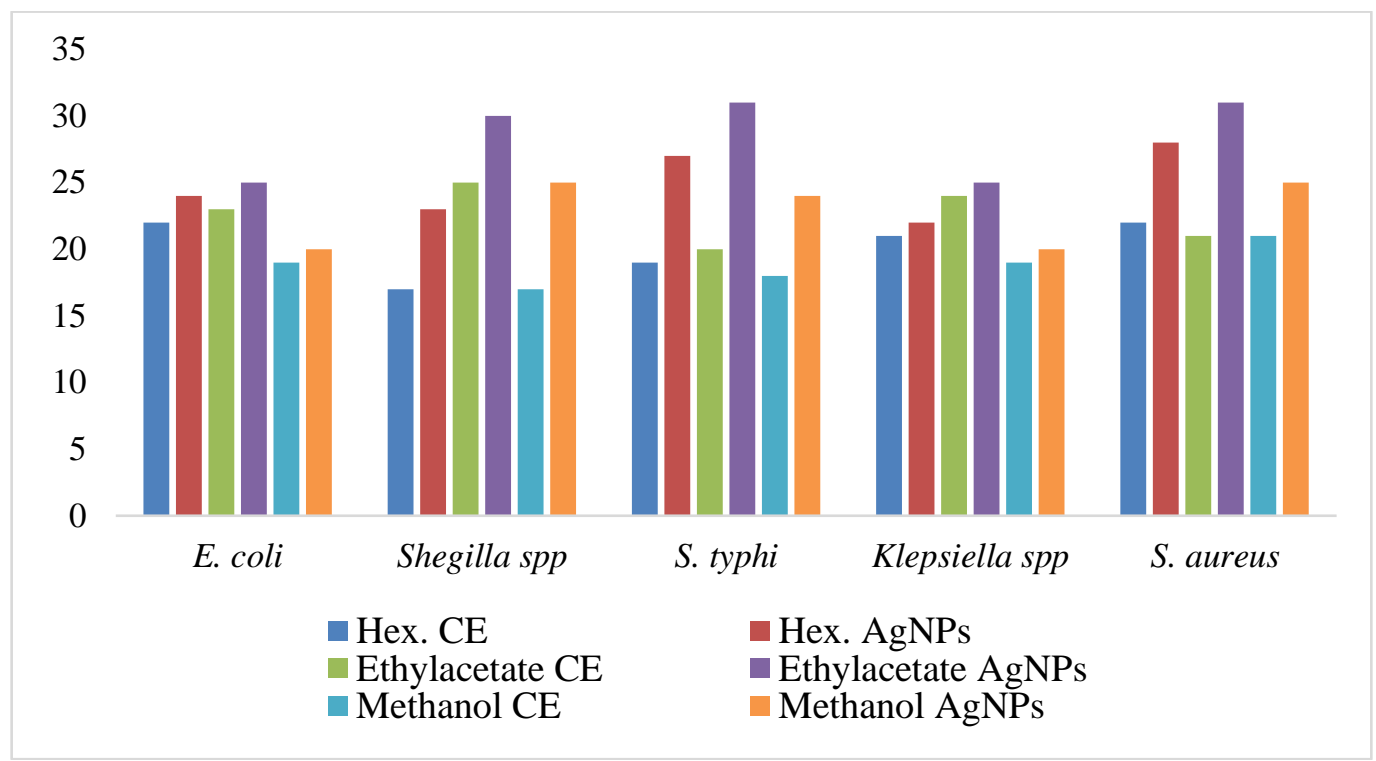

Fig. 3: Zone of Inhibition by the root of S. afzelii

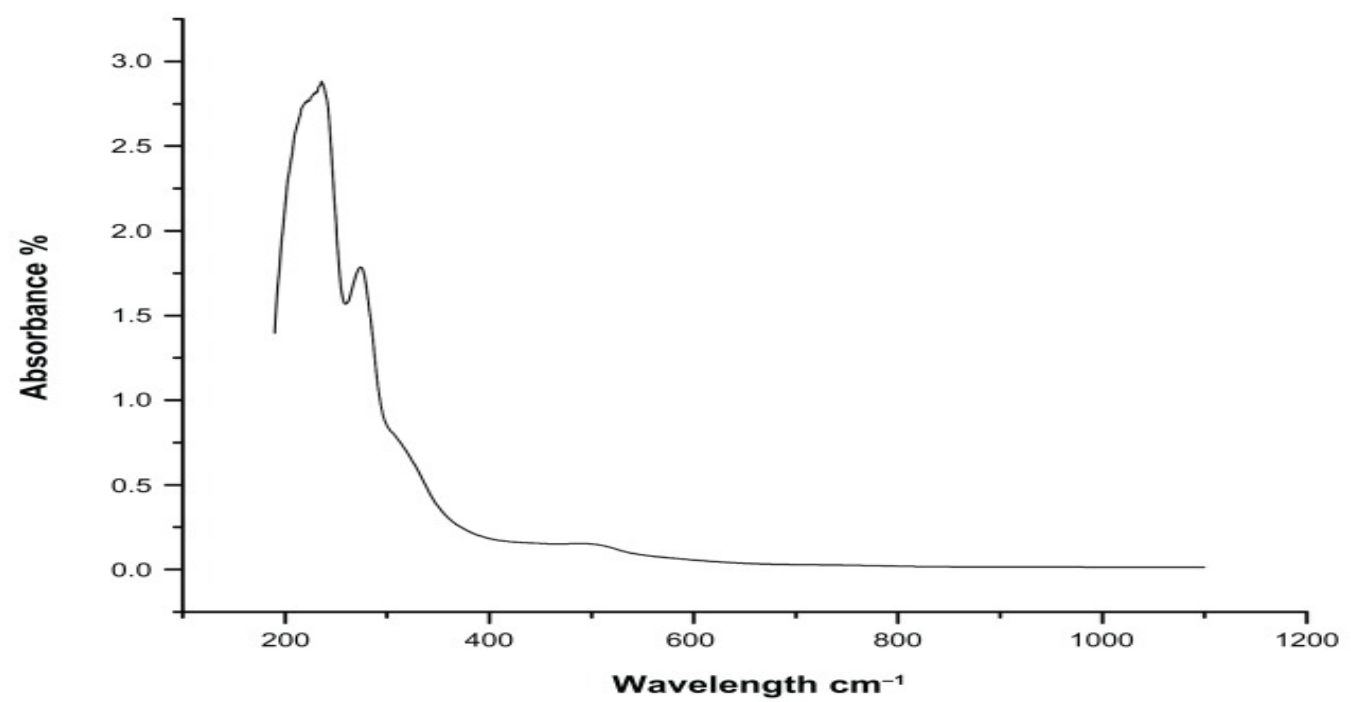

Fig. 4: UV-VIS Spectra of nanoparticles of S. afzelii methanol roots extract

\section{DISCUSSION}

In the present study, the percentage yield of extractions for the stem and root of $S$. afzelii was obtained using different polarity index of solvents namely haxane, ethyl acetate and methanol (Fig. 1) It is obvious from the figure that the methanol extract gave the highest percentage yield of extracts for all the solvent systems used, showing that extraction favors higher polar compounds ${ }^{[16]}$. It can also be observed that the root had more extract than the stem; these agree with Ali et al. ${ }^{[21]}$ and Troung et al. ${ }^{[16]}$.

The phytochemical screening carried out on the stem and root extracts of $S$. afzelii (Table 2), n-hexane extract showed seven phytochemicals out of the twenty (20) tested (two in the stem, five in the roots), seven were also revealed for ethyl acetate (two in the stem, three in the roots), while the methanol extract showed 15 phytochemicals present, with eight in the stem and seven in the roots. Polar solvents, usually have a higher extraction yield compared to non-polar solvents ${ }^{[17]}$, this is indicative in our result (Table $1 \&$ Fig. 1 ) as methanol extracts showed highest percentage yield and a corresponding higher Phytochemicals (Table 2) in agreement with literature ${ }^{[17]}$. More also, since both stem and root of the methanol extract contain the highest amount of the phytochemicals, this shows that methanol is the most suitable solvent for the extraction of phytochemicals in the stem and root of $S$. afzelii, as compared with n-hexane and ethylacetate. Phytochemical compounds in plants are biologically active compounds, which have medicinal potentials for the design and development of drugs, reports have 
shown that phytochemicals show a wide range of morphological activities ${ }^{[18,19]}$.

The antimicrobial activity of the crude extract and AgNPs carried out on the stem (Table 3 \& Fig. 2) and the root (Table 4 \& Fig. 3) show activities of all the microbes tested. It can be observed that AgNPs showed better zones of inhibition compared with the crude extract, it implies that the AgNPs have prospects for the development of antimicrobial drugs which may help against antibiotic-resistant genes. The root (Table 4 \& Fig. 3) specifically of the AgNPs showed a higher zone of inhibition. The antimicrobial activities can be attributed to the presence of bioactive compounds (phytochemicals) present in the stem and root of $S$. afzelii, which helped to reduce the $\mathrm{Ag}^{+}$to $\mathrm{Ag}^{\circ}$ and cap the molecules, thereby increasing the surface plasmon resonance.

The UV-visible spectra were performed to identify the compounds containing $\sigma$-bonds, $\pi$-bonds and lone pair of electrons, chromophores, and aromatic rings. The qualitative UV-Vis profile of methanolic extract of $S$. afzelii was taken at the wavelength of $200 \mathrm{~nm}$ to 1200 $\mathrm{nm}$ due to the sharpness of the peaks and proper baseline. The profile showed the peaks at $220 \mathrm{~cm}^{-1}$ and $260 \mathrm{~cm}^{-1}$ with the absorption 2.59 and 1.55 , respectively. The absorption spectrum of $\mathrm{S}$. afzelii extract and these are almost transparent in the wavelength region of 300$900 \mathrm{~nm}$. Absorption bands observed for S. afzelii plant extract is displayed in (Fig. 4). In the UV-Vis spectra, the appearance of one or more peaks in the region from 200 $\mathrm{nm}$ to $400 \mathrm{~nm}$ is an indication of the presence of unsaturated groups and heteroatoms such as S, N, O ${ }^{[20]}$. This confirms the presence of organic chromophores within the $S$. afzelii extract. The use of UV-Visible spectrophotometry in the analysis of complex media is limited by the inherent difficulties in assigning the absorption peaks to any constituents in the system. Thus, UV-Vis findings must be supplemented with some other analytical technique such as GC/MS to enable proper extract characterization and constituent identification.

\section{CONCLUSIONS}

Based on the various analysis carried out on this plant in the present study, it has been shown that methanol gave a better percentage yield and significant phytochemicals were also observed in the methanol extracts, which brings us to the conclusion that methanol was the most suitable of all the solvents for the extraction because of its polar nature and hence it has been able to extract out most of the polar biomolecules in the plant. More also, both crude extracts and synthesized AgNPs showed antibacterial activities, but AgNPs showed better activities than the crude extracts. Finally, this study has shown that the synthesized AgNPs of $S$. afzelii extracts have medicinal potentials and on further research can form the basis for the design and development of antibiotics that can have activity against resistant bacteria to curb the menace of antibiotic resistant genes or strands.

Furthermore, the study reveals that $S$. afzelii stem and root crude extracts possessed very useful phytochemicals, which could have potentials for the development of drugs on further isolation, purification, and identification to ascertain the medicinal phytochemicals and or biomolecules.

\section{ACKNOWLEDGMENTS}

We appreciate the Plateau State University, Bokkos, Plateau State, Nigeria for providing facilities for this research. No funding was released particularly for the research.

\section{CONTRIBUTION OF AUTHORS}

Research concept- Terver John Sase

Research design- Terver John Sase, Philomena Ayika

Materials- Philomena Ayika, Wushiba Habila Gorip, Job Dawulung

Data collection- Wushiba Habila Gorip, Job Dawulung

Data analysis and interpretation- Terver John Sase,Yilni Edward Bioltif

Literature search- Yilni Edward Bioltif, Wushiba Habila Gorip, Job Dawulung

Writing article- Yilni Edward Bioltif, Wushiba Habila Gorip, Job Dawulung

Critical review- Terver John Sase, Yilni Edward Bioltif Article editing- Yilni Edward Bioltif

\section{REFERENCES}

[1] Kamboj Ved P. Herbal medicine. Curr Sci., 2000; 78(1): 35-39.

[2] Newman DJ, Cragg GM, Snader, KM. The Influence of Natural Products upon Drug Discovery. Natural product reports, 2000; 17(3): 215-34.

[3] Ayandele AA, Adebiyi AO. The phytochemical analysis and antimicrobial screening of extracts of 
Olaxsubscorpioidea. Afr J Biotechnol., 2007; 6(7): 868-70.

[4] Odugbemi T. A textbook of medicinal plants from Nigeria. Revised Edition. University of Lagos Press: 2008: 20-23.

[5] Kawo AH, Suleiman ZA, Yusha'u M. Studies on the antibacterial activity and chemical constituents of Khaya senegalensis and Ximenia americana leaf extracts. Afr J Microbiol Res., 2011; 5(26): 4562-68.

[6] Arbonnier M. Trees, shrubs, and lianas of West African dry zones, CIRAD MARGRAF Publisher MNH. Wagningen, Netherlands. Quae, 2004; pp. 213-14.

[7] Arbonnier M. Trees, shrubs and lianas of West African dry zones, second revised and supplemented Edition, Margraf publisher, Weikersheim, Germany. GMBH, 2002; pp. 10-13.

[8] Ishola 10, Akindele AJ, Adeyemi OO. Analgesic and Anti-Inflammatory Activities of Cnestis ferruginea vahl Ex DC (Connaraceae) Methanolic Root Extract. J Ethnopharmacol., 2011; pp. 135-55. doi: 10.1016/j.jep.2011.02.024.

[9] Adje FA, Lozano YS, Adima AA, Chemat F. Antimicrobial Activities of Medicinal Plants. Int J Appl Res Natural Products, 2010; 4(2): 122-29.

[10]Knekt $P$, Kumpulainen J, Järvinen $R$, Rissanen $H$, Heliovaara M, et al. Am J Clin Nutr., 2002; 76 (3), 560. doi: 10.1080/10408398.2019.1632258.

[11]Ambe GA. Edible wild fruits of the Guinean savannahs of Cote-d'Ivoire: state of knowledge by a local population, the Malinké. Biotechnol. Agron. Soc. Approx., 2001; 5 (1): 43.

[12]Buru AS, Pichika MR, Neela V, Mohandas K. In vitro antibacterial effects of Cinna momum extracts on common bacteria found in wound infections with emphasis on methicillin-resistant Staphylococcus aureus. J Ethnopharmacol., 2014; 153(3): 587-95. doi: 10.1016/j.jep.2014.02.044.

[13]Evans WC. Trease and Evans Pharmacognosy, $16^{\text {th }}$ Edition. E-Book. Elsevier Health Sci., 2009; 7.

[14]lqbal GK, Hussain MA, Gimka YM. Development and clinical trial of nano-atropine sulfate dry powder inhaler as a novel organophosphorous poisoning antidot Appl Sci J., 2010; 9(7): 800-03.
[15]Yoder BJ. Isolation and structural elucidation of cytotoxic natural products from the rainforests of Madagascar and Suriname. A Ph. D in Chemistry Dissertation submitted to the Faculty of the Virginia Polytechnic Institute and State University, 2005; pp. 1.

[16]Troung D, Nguyen DH, Ta NTA, Bui AV, et al. Evaluation of the use of different solvents for phytochemical constituents, antioxidants and Invitro anti-flammatory activities of Severinia buxifolia. J Food Quality, 2019; pp. 1-9.

[17]Nur-Syukriah AR, Liza MS, Harisun Y, Fadzillah AAM. Effect of solvent extraction on antioxidant and antibacterial activities from Quercus infectoria (Manjakani). Int Food Res J., 2014; 21(3): 1031-37.

[18]Okwu DE, Okwu ME. Chemical composition of Spondias mombin Linn plant parts. J. Sustain Agric. Environ., 2004; 6(2): 140-47. doi: 10.12691/ajps3-11.

[19]Dada AO, Adekola FA, Dada FE, Adelani-Akande AT, et al. Silver nanoparticle synthesis by Acalypha wilkesiana extract: phytochemical screening, characterization, influence of operational parameters, and preliminary antibacterial testing. Heliyon, 2019; 5(10): e02517. doi: 10.1016/j.heliyon.2019.e02517.

[20]Mohan VR, Chenthurpandy P, Kalidass C. Pharmacognostic and phytochemical investigation of Elephantopus scaber L. (Asteraceae). J Pharmaceutical Sci Technol., 2010; 2: 191-97.

[21]Ali RM, Houghton PJ, Raman A, Hoult JRS. Antimicrobial and anti-inflammatory activities of extracts and constituents of Oroxy/um indicum (L.) Vent. Phytomedicine, 2018; 5(5): 375-81. doi: 10.1016/S0944-7113(93)80020-2.

[22] Rivera-Rangel RD, Gonzalez-Munoz MP, AvilaRodriguez M, Razo-Lazcano TA, Solans C. Green synthesis of silver nanoparticles in oil-in-water microemulsion and nano-emulsion using geranium leaf aqueous extract as a reducing agent. Coll Surf A: Physicochem Eng Asp., 2018; 536: 60-67. doi: 10.1016/j.colsurfa.2017.07.051. 